\title{
Pyrite surface interaction with selected organic aqueous species under anoxic conditions
}

\author{
Joakim Bebié and Martin A. A. Schoonen \\ Department of Geosciences, State University of New York at Stony Brook, Stony Brook, NY, \\ USA 11794-2100. E-mail: mschoonen@notes.cc.sunysb.edu
}

Received 11th July 2000, Accepted 29th September 2000

Published on the Web 23rd October 2000

\begin{abstract}
The interaction between low-molecular weight organic compounds and pyrite under anoxic conditions has been studied using a combination of electrophoresis and batch sorption experiments. The results suggest that acetate, carbamide, ethylamine, formamide, purine, D-ribose, and adenine, as well as the amino acids alanine, cysteine and glycine, interact within the electrophoretic shearplane of the pyrite surface. The observed surface interaction between the negatively charged surface of pyrite and the organic aqueous species takes place regardless of the formal charge of the aqueous species of interest. This indicates that the interaction of organic molecules with pyrite surfaces under anoxic conditions is dictated by interactions with specific surface sites (thiol or iron surface sites) rather than electrostatic forces. Dissolved metals typically enhance the interaction of the organics species. This enhancement is either due to an alteration in the distribution of thiol and iron groups on the pyrite surface or by the formation of ternary surface complexes.
\end{abstract}

\section{Introduction}

The fundamental principles underlying the surface chemistry of pyrite are of interest to a range of disciplines. Pyrite is ubiquitous in natural systems. For example, pyrite is found in anoxic marine sediments, ${ }^{1}$ submarine hydrothermal vent systems, ${ }^{2,3}$ terrestrial hot spring environments, ${ }^{4}$ and many anoxic groundwater systems. ${ }^{5,6}$ The separation of sulfide minerals in industrial flotation processes ${ }^{7-12}$ and the possible use of metal sulfides as photocatalysts ${ }^{13-16}$ relies on a thorough understanding of the surface chemistry of pyrite. Iron sulfides have also been suggested to play an important role in a surfacemediated chemoautrophic origin-of-life hypothesis. ${ }^{17-23}$ A key step in this chemoautrophic origin-of-life hypothesis is the sorption and subsequent transformation of low-molecular weight organic compounds, such as acetate, on the pyrite surface. Despite the wide-ranging interest in pyrite, comparatively little is known about the surface chemistry of pyrite under anoxic conditions.

It has often been assumed that pyrite and many other common metal sulfide minerals have a positive surface charge. This notion is largely based on work related to industrial metal-sulfide separation through froth flotation. However, froth flotation is typically performed in solutions containing dissolved molecular oxygen. The separation of metal sulfides is conducted in tanks open to the atmosphere and air is forced through the mineral slurries. ${ }^{24}$ It has been shown that incipient oxidation of pyrite changes its surface charge development drastically. ${ }^{25,26}$ The resulting charge development on an oxidized pyrite surface appears to be similar to the one observed for iron oxide or iron oxy-hydroxide. It is, therefore, of fundamental importance to distinguish between work that has been performed in the presence of molecular oxygen from investigations conducted under strictly anoxic conditions. Note that molecular oxygen is not the only common oxidant to induce pyrite surface oxidation. Many studies point to the observation that aqueous $\mathrm{Fe}^{3+}$ can promote oxidation of pyrite as well. ${ }^{27}$

The objective of this study is to investigate possible interaction of various types of organic molecules with pyrite as a function of $\mathrm{pH}$ and solution composition under anoxic conditions. There are several types of interaction that may occur between a sorbate and the pyrite surface. This interaction may be either non-specific (i.e., solely dictated by electrostatic forces) or specific (i.e., combination of electrostatic forces and specific chemical bonding). If an adsorbate is sorbed through a mechanism that involves the formation of a chemical bond then the species must be close enough to the surface to make the bond (compare Fig. 1a vs. 1b). Specific interaction may involve a central ion (inner-sphere complex, Fig. 1b) or one of its ligands (outer-sphere, Fig. 1c). The presence of specifically sorbed species within the stern layer of a charged surface alters the decrease of the electrical surface potential as a function of the distance from the surface. Sorption within the stern layer also affects the $\zeta$ (zeta) potential of the material. The $\zeta$ potential is the potential at the hydrodynamic shear plane, which is thought to be close in distance to the transition from the stern layer to the diffuse layer. Hence, by determining the $\zeta$ potential as a function of solution composition, it is possible to evaluate if the interaction between an aqueous species is specific or non-specific. It is of interest to determine both the partitioning and nature of the interaction between dissolved organic compounds and pyrite.

Understanding the interactions between aqueous species and mineral surfaces is of importance in understanding heterogeneous reactions that may take place on a mineral surface. For surface-mediated reactions to take place, the reactants must be first sorbed onto the surface. Sorbates are more likely to be involved in surface mediated reactions that involve formation and breaking of bonds if they are specifically bonded. ${ }^{28}$

\section{Previous studies}

In earlier studies it was determined that under anoxic conditions pyrite is negatively charged down to below $\mathrm{pH}=2$ in the absence of potential determining ions (PDI). ${ }^{25,26}$ The surface charge is strongly dependent on the presence of $\mathrm{Fe}^{2+}$ in solution. The addition of PDIs changes the $\mathrm{pH}-\zeta$-potential dependency considerably. ${ }^{25}$ Addition of $\mathrm{H}_{2} \mathrm{~S}(0.5 \mathrm{mM})$ results in more negative $\zeta$-potentials, whereas the addition of $\mathrm{Fe}^{2+}(0.5 \mathrm{mM})$ induces a shift in isoelectric point (IEP) to $\mathrm{pH}_{\mathrm{IEP}}=5$, below which pyrite becomes positively charged. Both findings are explained with a change 
(a)

(b)

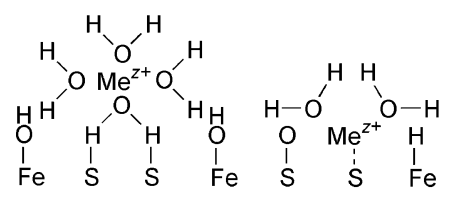

pyrite (100) surfaces have been found to differ from pyrite (111) surfaces. ${ }^{35}$ However, the acid-wash pretreatment used in this study has proven to be very effective in minimizing the defect densities on pyrite. ${ }^{34}$

It should be kept in mind that an electrophoretic measurement is essentially a snapshot of the sorbate-sorbent interaction after the slurry is adjusted to the desired $\mathrm{pH}$. For practical reasons it is not possible to keep the slurry at a given $\mathrm{pH}$ for more than $30 \mathrm{~min}$. This may not be sufficient time to ensure that equilibrium has been achieved. Hence, it is possible that if one could leave a slurry at a particular $\mathrm{pH}$ for an extended period of time (hours to days), a different result would be obtained. Whether sorbate-sorbent equilibrium has been attained in some slurries is not crucial since our main objective in these experiments is to determine if a species interacts specifically or non-specifically. In essence, we use electrophoresis as a 'screening method' which allows the investigation of fairly large matrices of possible surface interaction as a function of $\mathrm{pH}$ and solution composition. As pointed out above, those species that show specific interaction are of most interest. It is difficult to imagine a system in which a species shows specific interaction on a short time scale, but reverts to non-specific interaction as it approaches an equilibrium partitioning.

The selection of organic sorbates and solution composition was guided by the functionality of organic compounds and their possible interaction with dissolved $\mathrm{Fe}^{2+}$ as well as the pyrite surface. The effect of the presence of $\mathrm{Fe}^{2+}$ on sorbatepyrite interaction is of interest because of the high activity of $\mathrm{Fe}^{2+}$ in the near-surface region during pyrite precipitation and dissolution processes. The activity of $\mathrm{Fe}^{2+}$ is also of interest in the context of the origin of life. It has been estimated that the dissolved iron concentration in a Hadean (pre-Archean) ocean was above $0.1 \mathrm{mmol}^{36}$ The iron could have been released through deep-sea hydrothermal exhalative systems. ${ }^{37}$ Presentday hydrothermal solutions venting from 'black smokers' contain $\mathrm{Fe}^{2+}$ in millimolar concentration and appreciable amounts of $\mathrm{Cu}^{2+}$ as well. ${ }^{38}$ Metals such as $\mathrm{Fe}^{2+}$ and $\mathrm{Cu}^{2+}$ form stable complexes with organic compounds. ${ }^{39-42}$ Metal complexation could facilitate the uptake and retention of organic molecules on metal sulfide surfaces by the formation of ternary complexes. ${ }^{43}$

Organic molecules with different functional groups were chosen to evaluate a variety of possible interactions (Table 1). Acetate was chosen as a representative for a simple carboxylic acid. The selection of amino acids included alanine, glycine, cysteine and L-serine. All four amino acids have isoelectric points between $\mathrm{pH} 5$ and 6 , with $\mathrm{p} K_{\mathrm{a} 1}(\alpha-\mathrm{COOH})$ values between 2.0 and 2.3 , and a $\mathrm{p} K_{\mathrm{a} 2}\left(\alpha-\mathrm{NH}_{3}{ }^{+}\right)$between 9.2 and 10.3. Ethylamine $\left(\mathrm{CH}_{3} \mathrm{CH}_{2} \mathrm{NH}_{2}\right)$, formamide $\left(\mathrm{HCONH}_{2}\right)$ and carbamide $\left[\mathrm{CO}\left(\mathrm{NH}_{2}\right)_{2}\right]$ were investigated in order to investigate the effects of amine functional groups in simple organic molecules. Ethylamine is mostly present in form of the corresponding ammonium ion $\left(\mathrm{CH}_{3} \mathrm{CH}_{2} \mathrm{NH}_{3}{ }^{+}\right)$with a $\mathrm{p} K_{\mathrm{a}}$ value of 10.81. Adenine, its parent compound purine and $\mathrm{D}-$ ribose are included to investigate possible interaction of heterocycles and sugars with pyrite. Purine was included because of its delocalized electronic structure which could favour interaction with multiple surface sites on the mineral surface. Additionally, adenine and D-ribose are considered because of their precursor role in nucleotide and phosphate chemistry.

\section{Methods}

\subsection{Electrophoresis}

The objective of the electrophoretic mobility measurements was to determine if an organic compound sorbed specifically or non-specifically. Electrophoresis experiments were performed 
Table 1 Composition of solutions used in electrophoresis experiments

\begin{tabular}{|c|c|c|c|c|c|c|c|}
\hline Run & Molecule & Concentration & Ionic strength $\mathrm{I} / \mathrm{mM}$ & $\mathrm{Fe}^{2+}$ & Particle load/g $1^{-1}$ & $\mathrm{NaCl}$ & $\mathrm{SO}_{3}$ \\
\hline er-2 & Blank & - & 5.1 & - & 0.50 & 4.28 & 0.26 \\
\hline er-3 & $\mathrm{Fe}(\mathrm{II})$ & 0.5 & 5.2 & 0.50 & 0.50 & 0.83 & 0.29 \\
\hline er-50 & Adenine & 0.11 & 5.0 & - & 0.50 & 4.15 & 0.26 \\
\hline er-51 & Adenine $+\mathrm{Fe}^{2+}$ & 0.10 & 5.0 & 0.50 & 0.51 & 0.65 & 0.25 \\
\hline er-24 & Acetate $+\mathrm{Fe}^{2+}$ & 0.50 & 5.5 & 0.53 & 0.51 & 0.32 & 0.31 \\
\hline er-29 & Alanine $+\mathrm{Fe}^{2+}$ & 0.50 & 5.1 & 0.50 & 0.50 & 0.29 & 0.26 \\
\hline er-37 & Acetate & 0.51 & 5.1 & - & 0.50 & 3.78 & 0.27 \\
\hline er-38 & Alanine & 0.50 & 5.0 & - & 0.50 & 3.76 & 0.25 \\
\hline er-39 & Glycine & 0.52 & 5.0 & - & 0.51 & 3.76 & 0.25 \\
\hline er-30 & Glycine $+\mathrm{Fe}^{2+}$ & 0.52 & 5.3 & 0.50 & 0.51 & 0.53 & 0.24 \\
\hline er-52 & L-Serine & 0.12 & 5.0 & - & 0.50 & 4.15 & 0.25 \\
\hline er-6 & Cysteine & 0.50 & 4.9 & - & 0.51 & 2.79 & 0.37 \\
\hline er-21 & Cysteine $+\mathrm{Fe}^{2+}$ & 0.50 & 5.5 & 0.50 & 0.52 & 0.26 & 0.26 \\
\hline er-23 & Ethylamine & 0.50 & 5.0 & - & 0.51 & 3.75 & 0.26 \\
\hline er- 22 & Ethylamine $+\mathrm{Fe}^{2+}$ & 0.51 & 5.0 & 0.50 & 0.51 & 0.26 & 0.25 \\
\hline er- 47 & D-Ribose & 0.11 & 5.0 & - & 0.50 & 4.14 & 0.25 \\
\hline er-49 & D-Ribose $+\mathrm{Fe}^{2+}$ & 0.11 & 5.0 & 0.50 & 0.50 & 0.67 & 0.24 \\
\hline er-34 & Purine & 0.50 & 5.0 & - & 0.51 & 3.78 & 0.25 \\
\hline er-41 & Purine $+\mathrm{Fe}^{2+}$ & 0.50 & 5.1 & 0.50 & 0.50 & 0.27 & 0.27 \\
\hline er-26 & $\mathrm{Cu}^{2+}$ & 0.11 & 5.1 & - & 0.50 & 4.01 & 0.25 \\
\hline er-33 & $\mathrm{Fe}^{2+}$ & 0.11 & 5.0 & 0.11 & 0.51 & 3.55 & 0.25 \\
\hline er-32 & Carbamide & 0.45 & 5.0 & - & 0.52 & 3.76 & 0.25 \\
\hline er-40 & Carbamide $+\mathrm{Fe}^{2+}$ & 0.51 & 5.0 & 0.50 & 0.50 & 0.25 & 0.26 \\
\hline er-55 & Formamide & $0.7^{a}$ & 5.6 & - & 0.51 & 4.15 & 0.26 \\
\hline er-56 & Formamide $+\mathrm{Fe}^{2+}$ & $0.7^{a}$ & 5.6 & 0.50 & 0.50 & 0.64 & 0.25 \\
\hline
\end{tabular}

following the protocol outlined in an earlier study. ${ }^{25}$ In brief, crushed pyrite (Huanzala, Peru) was acid-washed and $\mathrm{H}_{2} \mathrm{O}-$ washed (both free of dissolved $\mathrm{O}_{2}$ ) under an $\mathrm{N}_{2}$ atmosphere. This treatment has been shown to yield a clean and stoichiometric surface. ${ }^{34}$ Particles were subsequently dried under vacuum and then resuspended in deoxygenated aqueous solutions of well-defined composition. Suspensions were kept in the dark during handling to prevent possible photochemical reactions. All electrophoresis experiments were performed in $5 \mathrm{mmol} \mathrm{NaCl}$ supporting electrolyte solution at $20^{\circ} \mathrm{C}$. The potential distribution and its dependence on ionic strength have been discussed elsewhere. ${ }^{30}$ The $\mathrm{pH}$ was adjusted by adding $\mathrm{HCl}$ and $\mathrm{NaOH}$. The important parameters of each experiment are listed in Table 1. Note that it is unfeasible to perform experiments in seawater because the high ionic strength causes a rapid electrical surface potential drop-off, as a function of distance from particle, which results in a zero $\zeta-$ potential measurement.

Most electrophoresis experiments were completed within $3 \mathrm{~h}$ to limit possible transformations of some of the less stable organic compounds used in this study. Deamination, dehydrogenation or oxidation reactions are not expected under the experimental conditions. A sulfonation or sulfo-dehydrogenation reaction between sulfite, added to removing traces of dissolved oxygen from the pyrite slurries, ${ }^{25}$ and ethylammonium could have proceeded. However, the ethylamine was added in excess of sulfite. Furthermore, the reaction of sulfite with remaining molecular oxygen to form sulfate is very rapid and is likely to consume most of the sulfite present. Formamide and carbamide acidic and basic hydrolysis with $\mathrm{NH}_{2}$ elimination is unlikely under the mild conditions. ${ }^{44}$ Traces of $\mathrm{HS}^{-}$ could potentially react through a nucleophilic addition to the carbonyl carbon to form thioformate and thioamide. At room temperature and the time period involved $(\sim 3 \mathrm{~h})$ it is thought to be of minor importance. The resonance-stabilized amides are nonbasic and poor nucleophiles. Typically, no ions are formed with aqueous acids.

\subsection{Sorption experiment}

The electrophoresis experiments with acetate were complemented by a batch sorption experiment to quantify its uptake.
The sorption experiment was conducted under controlled $\mathrm{N}_{2}$ atmosphere in a water-jacketed 11 reaction vessel wrapped in aluminum foil to prevent possible photochemical reactions during the experiment. The particles were prepared following the same procedure as described for the electrophoresis experiments. The deionized water was of milli-Q quality (18 $\mathrm{M} \Omega$, filtered $0.22 \mu \mathrm{m}$ ). Aliquots (about $1.5 \mathrm{ml}$ ) were taken with $3 \mathrm{cc}$ plastic syringes through Teflon tubing and then filtered through $0.2 \mu \mathrm{m}$ polycarbonate membranes.

\subsection{Analytical techniques}

The iron concentrations for the electrophoresis experiments were determined by atomic absorption spectrometry (AAS) or inductively-coupled plasma atomic emission spectroscopy (ICP-AES, Varian 5E). Iron analysis in the sorption experiments was carried out spectrophotometrically with a Hach DR/ 2000 using the FerroZine ${ }^{\mathrm{B}}$ method \#8147. Acetate was analyzed by ion chromatography (Dionex 2000I) and purine by UV-VIS spectroscopy.

\subsection{Speciation calculations}

The chemical speciation program PHREEQE, which is based on an ion-pairing model, was used to calculate the aqueous speciation of compound of interest. ${ }^{45}$ The speciation of a compound dictates which aqueous species could possibly interact with pyrite at a given $\mathrm{pH}$. The dissociation constants for the organic and inorganic ions, as well as the stability constants for $\mathrm{Fe}^{2+}$ complexes with the organic molecules, were taken from existing compilations. ${ }^{46}$

\section{Results}

\subsection{Electrophoresis}

All electrophoresis results are shown in Fig. 2 through Fig. 8. The $\zeta$-potential is plotted against $\mathrm{pH}$, which is measured in the range from 2-11. All the curves measured on suspensions containing $\mathrm{Fe}^{2+}$ or $\mathrm{Cu}^{2+}$ converge to zero $\zeta$-potential near a $\mathrm{pH}$ value of 8 (Fig. 2). This is the result of the collapse of the colloidal dispersion induced by the precipitation of iron and copper hydroxides. Therefore, the interpretation of results 


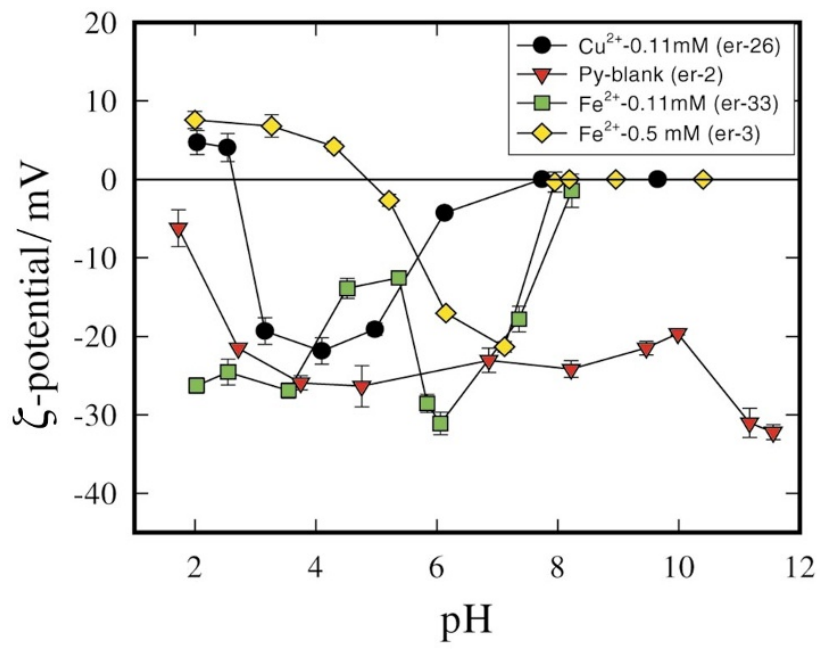

Fig. 2 Effect of $0.1 \mathrm{mM} \mathrm{Fe}^{2+}$ (er-33), $0.5 \mathrm{mM} \mathrm{Fe}^{2+}$ (er-3) and $0.1 \mathrm{mM}$ $\mathrm{Cu}^{2+}$ (er-26) on the $\zeta$-potential of a pyrite suspension kept under anoxic conditions. For reference, in experiment er-2 no metal was added. Starting ionic strength for each experiment was $5 \mathrm{mM}, \mathrm{NaCl}$ supported. For further parameters see Table 1.

from such experiments is limited to a $\mathrm{pH}$ value below 8 . The presence of $\mathrm{Fe}^{2+}$ or $\mathrm{Cu}^{2+}$ induces either a shift in isoelectric
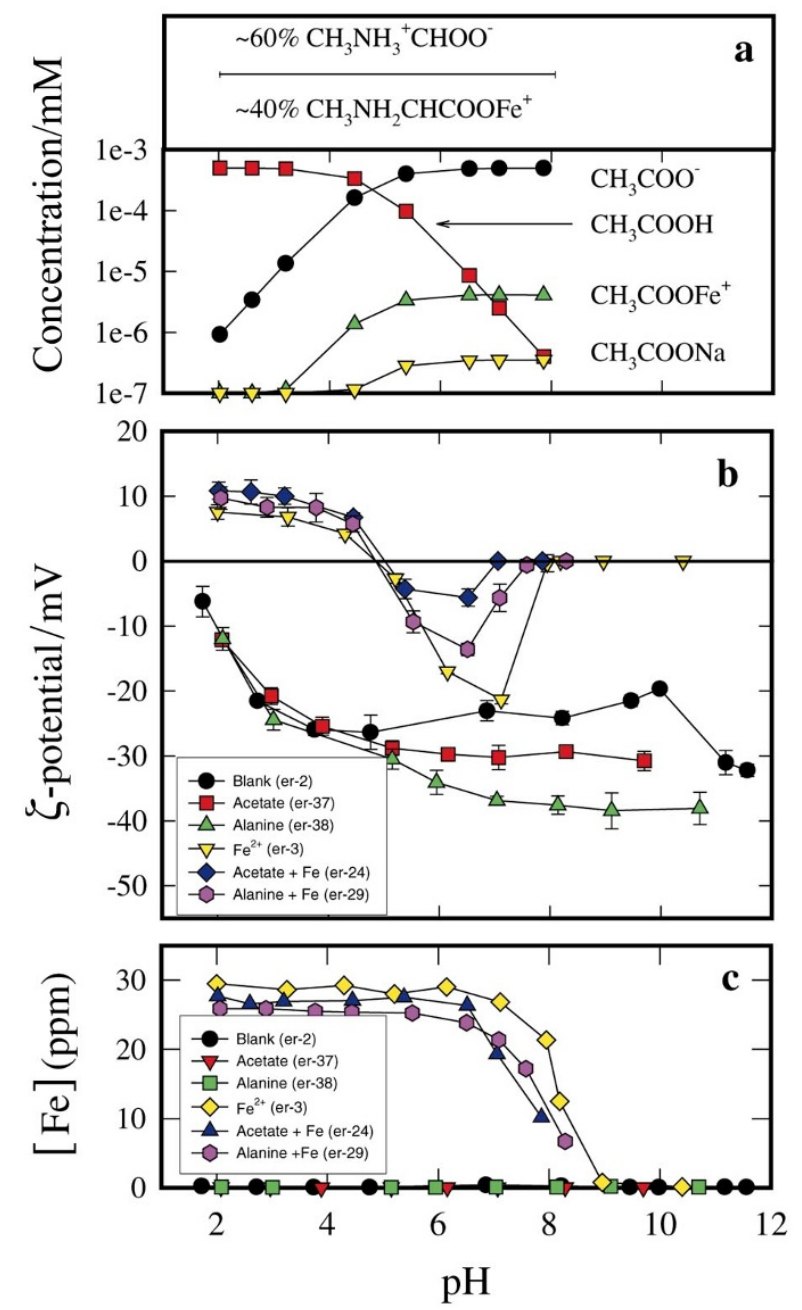

Fig. 3 Interaction of acetate and alanine with pyrite. (a) Aqueous speciation distribution as a function of $\mathrm{pH}$. (b) Curves er-37 (no added $\left.\mathrm{Fe}^{2+}\right)$ and er-24 [0.5 mM Fe( $\left.\left(\mathrm{NH}_{4}\right)\left(\mathrm{SO}_{4}\right)_{2}\right]$ were measured in $0.5 \mathrm{mM}$ acetate suspensions, whereas curves er-38 (no added $\mathrm{Fe}^{2+}$ ) and er-29 [0.5 mM Fe( $\left.\left(\mathrm{NH}_{4}\right)\left(\mathrm{SO}_{4}\right)_{2}\right]$ were obtained measuring $0.5 \mathrm{mM}$ alanine suspensions.

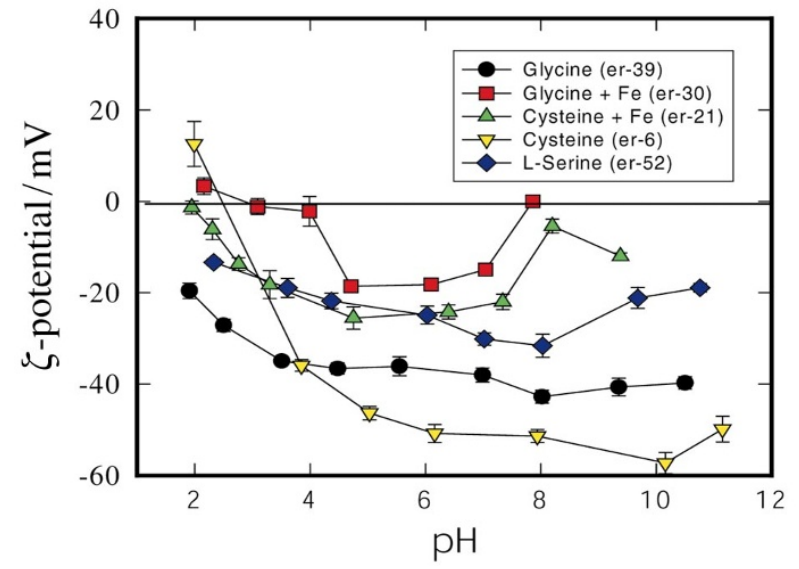

Fig. 4 Interaction of L-serine (er-52, no $\mathrm{Fe}^{2+}$ ), glycine (er-39, no $\mathrm{Fe}^{2+}$ and er-30, 0.5 mM Fe ${ }^{2+}$ ) and cysteine (er-6, no $\mathrm{Fe}^{2+}$ and er-21, $0.5 \mathrm{mM} \mathrm{Fe}^{2+}$ ) with pyrite.

points (IEP) or a significant change in the trend of the potential as a function of $\mathrm{pH}$. This observation can be interpreted in terms of interaction of the specific aqueous species within the electrophoretic shearplane of the particles. As shown for the case of $\mathrm{Fe}^{2+}$, the $\zeta$-potential is strongly dependent on the activity of metal ion in solution (Fig. 2). Once the $\mathrm{Fe}^{2+}$ concentration reaches $0.5 \mathrm{mM}$, a charge reversal is observed at $\mathrm{pH}$ 5. This effect has been observed earlier and discussed in detail. $^{25}$

The electrophoresis results for the acetate and alanine experiments are strikingly similar. Up to a $\mathrm{pH}$ of about 5 they both follow the reference curve (no added PDIs); above $\mathrm{pH} 5$ both deviate from the reference curve (Fig. 3(b)). It is noteworthy that around $\mathrm{pH} 5$, the de-protonated species, $\mathrm{CHCOO}^{-}$and $\mathrm{CH}_{3} \mathrm{CH}_{2} \mathrm{NH}_{2} \mathrm{COO}^{-}$, become the predominant acetate and alanine species. This change in speciation may contribute to the deviation from the reference curve (Fig. 3(a)). In the presence of $\mathrm{Fe}^{2+}$, it is expected that alanine and acetate form iron complexes $\left(\left[\mathrm{CH}_{3} \mathrm{NH}_{2} \mathrm{CHCOOFe}\right]^{+}\right.$and $\left[\mathrm{CH}_{3} \mathrm{COO}-\right.$ $\mathrm{Fe}]^{+}$), which then can interact with surface sulfur sites. ${ }^{42}$ It should be kept in mind that the speciation in experiments with iron is $\mathrm{pH}$ dependent. As the $\mathrm{pH}$ of the slurry is increased to 8 , the total iron concentration drops off drastically due to hydroxide precipitation (Fig. 3(c)). Hence, as the iron is largely removed from solution there is little or no dissolved iron left to form complexes with alanine or acetate.

Electrophoretic measurements in the presence of amino acids other than alanine show a range of different degrees of interaction. L-serine interacts little with pyrite (Fig. 4), at least in the absence of $\mathrm{Fe}^{2+}$. Glycine shows interaction in the presence of $\mathrm{Fe}^{2+}$ shifting the IEP to a $\mathrm{pH}$ value of 3 . Cysteine displays a very strong interaction (Fig. 4), possibly via its thiol-group with sulfur-deficient (iron-rich) surface sites. Addition of iron enhances the interaction between cysteine and pyrite. In the presence of both $\mathrm{Fe}^{2+}$ and cysteine the $\zeta$-potential is negative down to a $\mathrm{pH}$ value of about 2. Cysteine is known to form strong complexes with transition metals. The added $\mathrm{Fe}^{2+}$ may serve as 'bridging agent' between the cysteine thiol group and the sulfur surface sites of pyrite.

Formamide interacts with pyrite above $\mathrm{pH} 5$ and shifts, in the presence of $\mathrm{Fe}^{2+}$, the IEP to pH 6 (Fig. 5). Carbamide behaves distinctly differently in the presence of $\mathrm{Fe}^{2+}$, reversing the potential trend in the acidic $\mathrm{pH}$ region. Experiments with ethylamine suggest that this compound has an affinity towards pyrite above $\mathrm{pH} 4$ in the absence of $\mathrm{Fe}^{2+}$ (Fig. 6).

The interaction of adenine with pyrite modifies the $\zeta$ potential substantially as well, since it introduces shifts in 


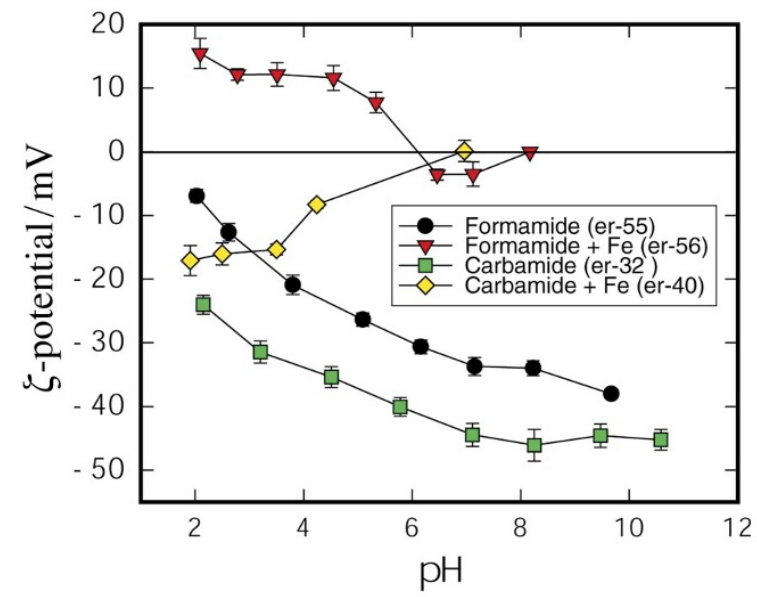

Fig. 5 Interaction of formamide (er-55, no $\mathrm{Fe}^{2+}$ and er-56, $0.5 \mathrm{mM}$ $\mathrm{Fe}^{2+}$ ) and carbamide (er-32, no $\mathrm{Fe}^{2+}$ and er-40, $0.5 \mathrm{mM} \mathrm{Fe}^{2+}$ ) with pyrite.

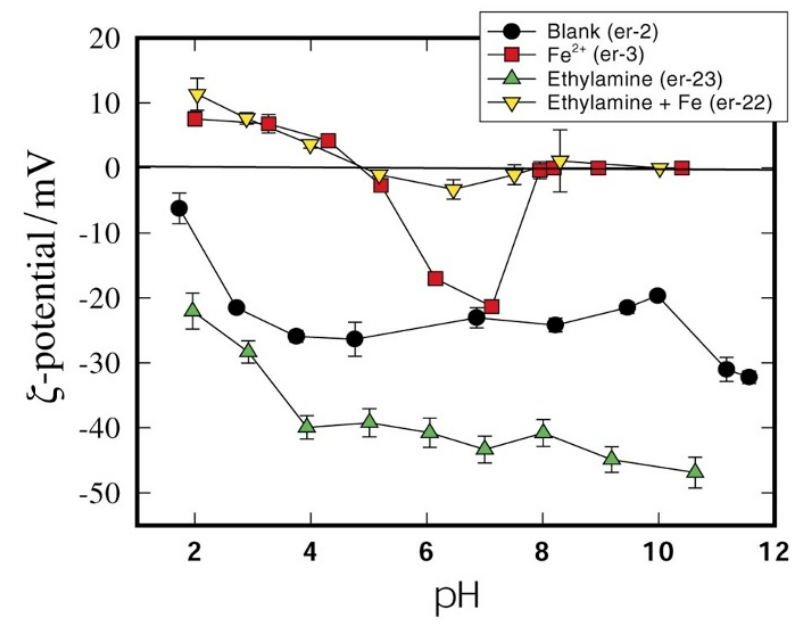

Fig. 6 Interaction of ethylamine with pyrite (a) in the absence of $\mathrm{Fe}^{2+}$ (er-23) and in the presence of $0.5 \mathrm{mM} \mathrm{Fe}^{2+}(\mathrm{er}-22)$.

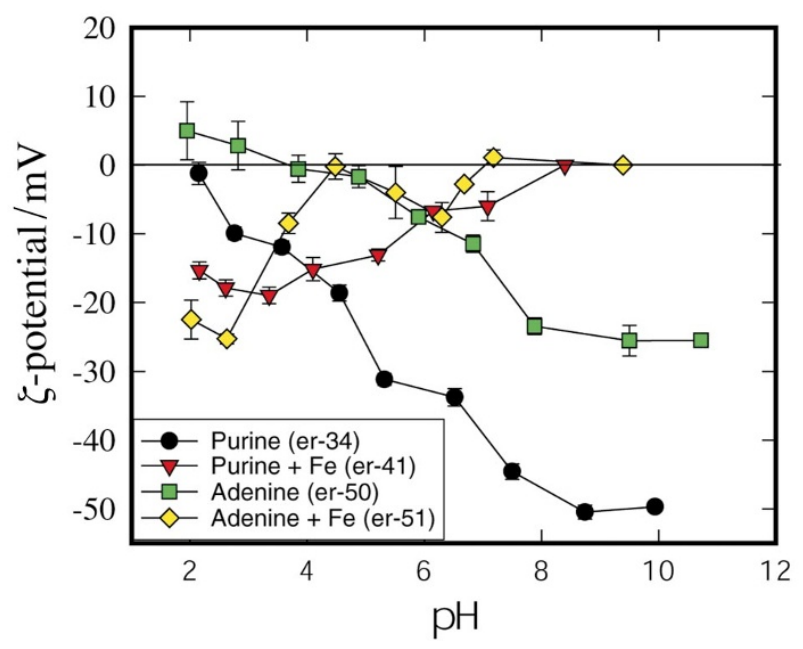

Fig. 7 Change of $\zeta$-potential with the addition of $0.1 \mathrm{mM}$ adenine to a pyrite suspension, in the absence of iron (er-50) and in the presence of $0.5 \mathrm{mM} \mathrm{Fe}{ }^{2+}$ (er-51). Note that er-51 was conducted with a 5-fold excess of iron compared to adenine (see Table 1). Interaction of purine with pyrite (a) in the absence of $\mathrm{Fe}^{2+}(\mathrm{er}-34)$ and in the presence of $0.5 \mathrm{mM} \mathrm{Fe}^{2+}(\mathrm{er}-41)$.

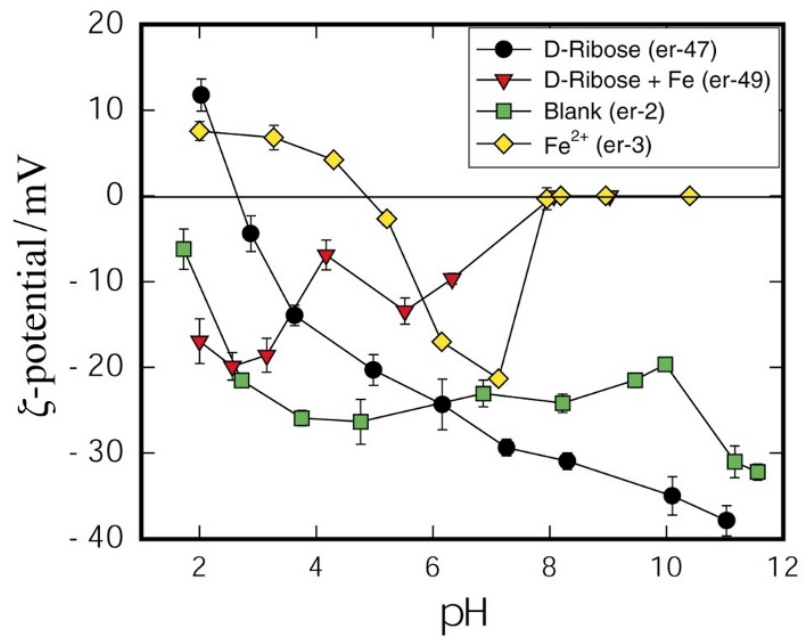

Fig. 8 Interaction of D-ribose with pyrite (a) in the absence of $\mathrm{Fe}^{2+}$ (er$47)$ and in the presence of $0.5 \mathrm{mM} \mathrm{Fe}^{2+}(\mathrm{er}-49)$.

$\mathrm{pH}_{\text {IEP }}$ (Fig. 7). This experiment suggests that adenine is residing within the electrophoretic shearplane of pyrite below $\mathrm{pH}$ 8. Similarly, purine shows strong interaction, especially in the presence of $\mathrm{Fe}^{2+}$ where the expected charge reversal below pH 5 is not observed (Fig. 7). The aqueous purine concentration remained the same $(\sim 60 \mathrm{ppm})$ over the entire measured $\mathrm{pH}$ range. D-ribose was found to affect the $\zeta$-potential significantly as well, shifting the IEP to $\mathrm{pH} 3$ (in the absence of $\mathrm{Fe}^{2+}$ ) and suppressing charge reversal in the presence of $\mathrm{Fe}^{2+}$ (Fig. 8).

\subsection{Acetate sorption}

A multi-step sorption experiment investigating the interaction of acetate with pyrite was performed. In a first step the Naacetate $(315 \mu \mathrm{M})$ was added to a pyrite suspension $\left(10 \mathrm{~g} \mathrm{~L}^{-1}\right)$ that had been equilibrated for $24 \mathrm{~h}$ at $\mathrm{pH}=4$ (Fig. 9, [1]). During that equilibration time, anoxic dissolution of pyrite released about $100 \mu \mathrm{M}$ of $\mathrm{Fe}^{2+}$ (Fig. 9(b), [1]). Uptake of acetate was then monitored over a period of $24 \mathrm{~h}$ at which point $6 \%$ of acetate had sorbed (Fig. 9(a), [1]). The $\mathrm{pH}$ was then increased to 7 which resulted in $\mathrm{Fe}(\mathrm{OH})_{2}$ precipitation (Fig. 9(b), [1]) but no change in acetate concentration was observed (Fig. 9(a), [1]). After $100 \mathrm{~h}, 390 \mu \mathrm{M}$ of $\mathrm{CuCl}_{2}$ were added which increased acetate sorption to $10 \%$ (Fig. 9(a), [2]). The addition of the acidic $\mathrm{CuCl}_{2}$ solution lowered the $\mathrm{pH}$ temporarily to 5 which was subsequently increased to 7 again. The measured $\mathrm{Cu}^{2+}$ concentration in solution never exceeded $40 \mu \mathrm{M}$ which means that at least $90 \%$ of the added $\mathrm{Cu}^{2+}$ was sorbed onto pyrite at any given time (Fig. 9(b), [2]). A day later $(t=129 \mathrm{~h})$, the $\mathrm{pH}$ was lowered to 6 and $530 \mu \mathrm{M}$ of $\mathrm{Fe}^{2+}$ [added as $\mathrm{Fe}\left(\mathrm{NH}_{4}\right)_{2}\left(\mathrm{SO}_{4}\right)_{2}$ ] was added which promoted sorption of acetate to the $14 \%$ level (Fig. 9(a), [3]). After $150 \mathrm{~h}$ the $\mathrm{pH}$ was lowered again to a $\mathrm{pH}$ value of 4 upon which the $\mathrm{Fe}^{2+}$, and, to a smaller extent $\mathrm{Cu}^{2+}$, slowly desorbed. Subsequently, under acidic conditions the iron concentration kept increasing with time. Copper, on the other hand, initially increasing in concentration somewhat, decreased to concentrations lower than $1 \mu \mathrm{M}$. Thus, it appears as if $\mathrm{Cu}^{2+}$ was replacing the $\mathrm{Fe}^{2+}$ sites on the pyrite surface (Fig. 9(b), [4]).

\section{Discussion}

The experiments demonstrate that anionic, zwitterionic, cationic and non-ionic molecules interact with the pyrite surface through the formation of chemical bonds (with the possible exception of serine). Even though the overall surface charge of pyrite is negative under anoxic conditions in the 


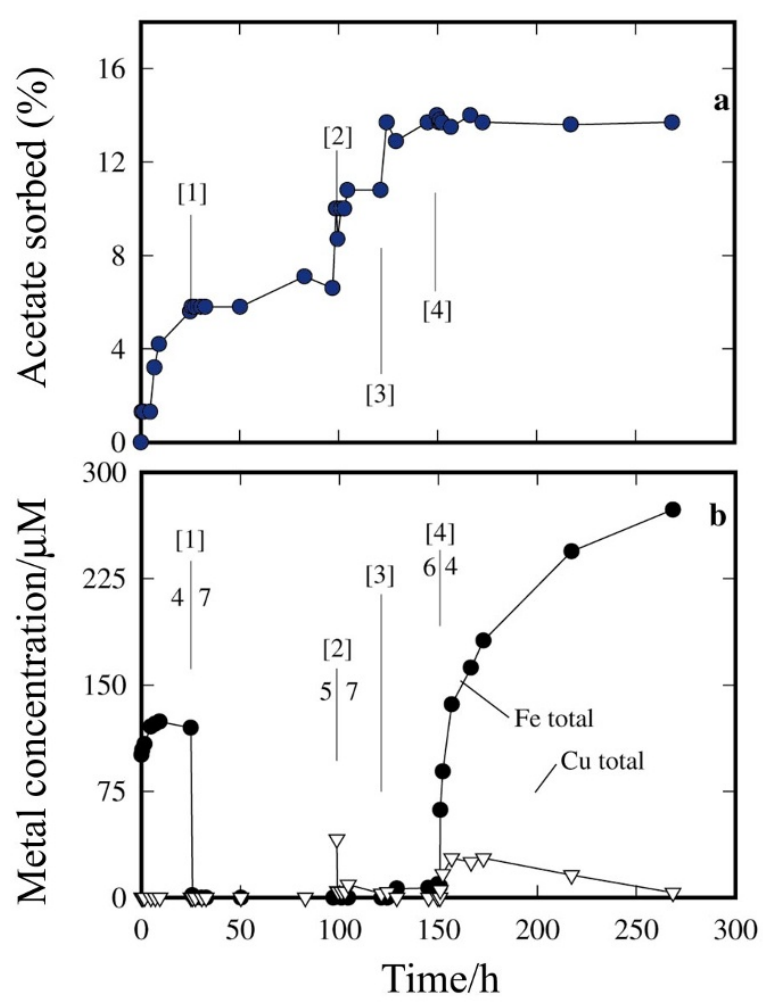

Fig. 9 Sorption of acetate onto pyrite (a) and its corresponding aqueous metal concentration (b) as a function of time. Note additional information indicating $\mathrm{pH}$ changes and times of $\mathrm{Cu}^{2+}$ and $\mathrm{Fe}^{2+}$ addition during the experiment ([1] through [4], see text).

absence of aqueous metal ions, anionic organic molecules, such as acetate, can overcome overall Coulombic repulsion and interact with the mineral surface. The nature of adsorbatepyrite interaction is therefore not limited to simple overall electrostatic attraction or repulsion but must include specific chemical interactions that are governed by localized forces. As pointed out in our study on phosphate-pyrite interaction, we think that anions can bind specifically with iron sites on the pyrite surface, thus overcoming the electrostatic repulsion forces near the surface. However, spectroscopic studies, which provide insight into sorbate-sorbent interaction on the molecular scale, are needed to support such conjectures.

As exemplified by the acetate sorption experiment, the interaction between organics and the pyrite is enhanced by the presence of $\mathrm{Fe}^{2+}$ and $\mathrm{Cu}^{2+}$ in solution. The added metal ions may enhance the interaction by either modifying the surface or by forming ternary complexes. The distribution of thiol and iron surface functional groups on the pyrite surface is a function of the concentration of PDIs in solution. An increase in the iron activity in solution will increase the abundance of iron groups on the surface providing more sites suitable for negatively charged species to interact with. The added metals can also enhance the interaction by first forming an aqueous metal-organic complex and then sorbing onto the surface, perhaps preferentially on thiol sites with the metal as a bridging atom. The interaction of heterocyclic compounds, such as adenine and purine, may involve interaction with one or more surface sites via induced dipole-dipole interaction. ${ }^{47}$ For example, by laying flat on the pyrite surface, adenine could interact with several iron sites at once. Detailed surface spectroscopic studies and high-level ab initio molecular orbital calculations are needed to resolve the geometry and electronic interaction between organic adsorbates and the pyrite surface. Such approaches are now becoming available. For example, recent work by Rosso and co-workers has demonstrated that the non-binding d-orbitals of pyrite play a key role in the interaction between adsorbed molecular oxygen and pyrite. ${ }^{48}$ We speculate that much of the interaction between the organic model compounds and pyrite is through these same orbitals.

The finding that the interaction of organic aqueous species with pyrite surfaces under anoxic conditions cannot be described satisfactorily using overall surface charge arguments can tentatively be extended to other transition metal sulfides. Earlier work has shown that most if not all metal sulfides show very similar surface charge development in the absence of PDIs. ${ }^{25}$

\section{Implications}

The fact that metal sulfide surfaces contain at least two types of surface functional groups as opposed to one ( $c f$. metal oxides ${ }^{49}$ ) has some interesting implications. A multiple-site surface, such as the pyrite surface, offers the possibility to bind species that are chemically different; one species binding to the thiol surface group, the other binding to the iron surface group. Subsequent interaction, such as electron transfer, between the co-adsorbates may produce products that would be difficult to form on a surface with a single surface site. Given the fact that pyrite is a semiconductor, electron transfer between co-adsorbates does not necessarily have to involve a direct transfer between the co-asorbates. Earlier work in our group has shown that co-adsorbates can exchange electrons by injecting and withdrawing electrons from the semiconductor. ${ }^{50-52}$ The importance of this is that the co-adsorbates only require orbital overlap with surface atoms and not with each other. Hence, co-adsorbates that may not react in solution because a suitable orbital overlap can not be formed may react on the surface of a semiconductor with multiple surface sites. Besides the thiol and iron surface groups, the pyrite surface may also contain uncharged, non-hydrolyzed sites (Fig. 1, site d). Such surface sites do not contribute to the surface charge on pyrite, but they could interact with molecular species via non-electrostatic modes of interaction. Similarly to a mechanism proposed for zeolites, ${ }^{53}$ neutral surface species may allow for bonding of organic molecules, which may subsequently react with sorbates held on the ionic surface sites.

Partial oxidation of a pyrite surface leads to the formation of a heterogeneous surface with $\mathrm{Fe}$-oxide patches decorating the pristine surface. ${ }^{54,55}$ The presence of the patches establishes a $\mathrm{Fe}-\mathrm{OH}$ surface functional group with binding properties that differ from those on the pristine surface. This would further enhance the possibilities for complex reactions to take place on a pyrite surface. It may also lead to segregation of sorbates on the surface. Species forming strong bonds with thiol groups (e.g., $\mathrm{Au})$ would accumulate on the pristine surface; while species forming strong bonds with $\mathrm{Fe}-\mathrm{OH}\left(\right.$ e.g., $\mathrm{PO}_{4}{ }^{3-}$ ) would preferentially bind to the patches. For example, it has been shown that Au sorption is stronger onto pyrite than onto goethite, $\mathrm{FeOOH} .{ }^{56}$ At the edges of the patches sorbates bond to the pristine surface and sorbates bond to the patches could interact, yielding product that could not be formed on either a pristine pyrite surface or an Fe-oxide surface.

The results presented in this study underscore the importance of dissolved metals in modifying the interaction between the adsorbate and the pyrite surface. This has some interesting implications for prebiotic synthesis of organic molecules at exhalative submarine vent systems involving pyrite as 'catalytic' surface as proposed by Wächtershäuser. ${ }^{17}$ Because the interaction of organic molecules and the pyrite surface is dependent on the metal concentration in solution, the metal to sulfide concentration in the vent solution becomes important. 
In metal-rich solutions, precipitation of metal sulfides will leave some metal in solution, but metal sulfide precipitation from sulfide-rich solutions will effectively remove all metal from solution. Metal-rich solutions would appear to be better suited for the types of surface reactions that were proposed by Wächtershäuser. It is also interesting to observe that both Dribose and adenine interact with pyrite. It has been reported earlier that adenosine and 5'-adenosinemonophosphate (5'AMP) interact with pyrite under similar conditions. ${ }^{29}$ Recently, the monolayer ordering of 2,6-dioxopurine on $\mathrm{MoS}_{2}$ has been reported. ${ }^{57}$ This opens up the possibility that there may exist pathways for nucleotide synthesis on metal sulfide surfaces. The actual assembly of a nucleotide, however, remains to be shown.

\section{Conclusion}

The results of this study suggest that the interaction of a wide range of low-molecular weight organic compounds is dictated by interactions with specific surface sites and not by overall electrostatic forces. Spectroscopic studies are needed to resolve the exact nature of the specific sorbate-sorbent interactions. The presence of dissolved metals typically enhances the interaction, but the exact mechanism cannot be resolved with the techniques used in this study. Sorption of acetate onto pyrite is enhanced by the presence of $\mathrm{Fe}^{2+}$ and $\mathrm{Cu}^{2+}$.

\section{Acknowledgements}

This work has been supported by NASA's Exobiology Program. We thank Dr Mark Fuhrmann (Brookhaven National Laboratory) for making the electrophoresis equipment, ICP-AES- and AA-equipment available. This paper is based on the $\mathrm{PhD}$ dissertation of the senior author. We thank two anonymous reviewers for their constructive comments.

\section{References}

1 R. A. Berner, Sedimentary pyrite formation: An update, Geochim. Cosmochim. Acta, 1984, 48, 605.

2 M. D. Hannington, I. R. Jonasson, P. M. Herzig and S. Petersen, in Seafloor hydrothermal systems, ed. S. E. Humphris, R. A. Zierenberg, L. S. Mullineaux and R. E. Thomson, American Geophysical Union, Washington, DC, 1995, p. 115.

3 M. K. Tivey, in Seafloor hydrothermal systems, ed. S. E. Humphris, R. A. Zierenberg, L. S. Mullineaux and R. E. Thomson, American Geophysical Union, Washington, DC, 1995, p. 158.

4 A. L. Day and E. T. Allen, Volcanic activity and hot springs of Lassen Peak, Carnegie Institute of Washington, Washington, DC, 1925.

5 C. J. Brown, J. Rakovan and M. A. A. Schoonen, Heavy mineral and sedimentary organic matter in Pleistocene and Cretaceous sediments on Long Island, New York, with emphasis on pyrite and marcasite in the Magothy aquifer, Water-Resources Investigation Report, 99-4216, USGS, Coram, NY, 1999.

6 F. Larsen and D. Postma, Environ. Sci. Technol., 1997, 31, 2589.

7 M. C. Fuerstenau, M. C. Kuhn and D. A. Elgillani, Trans. Am. Inst. Mining Met. Petroleum Eng., 1968, 241, 148.

8 D. Hornsby and J. Leja, Selective flotation and its surface chemical characteristics, ed. E. Matijevic, Plenum Publishing Corp., New York, 1982.

9 K. A. Kydros, G. P. Gallios and K. A. Matis, J. Chem. Technol. Biotechnol., 1994, 59, 223.

10 R. L. Pozzo and I. Iwasaki, J. Electrochem. Soc., 1989, 136, 1734.

11 X. H. Wang, J. Colloid Interface Sci., 1995, 171, 413.

12 X. H. Wang, J. Colloid Interface Sci., 1996, 178, 628

13 A. J. Bard, J. Chem. Phys., 1982, 86, 172.

14 C. Y. Liu and A. J. Bard, J. Phys. Chem., 1989, 93, 7047.

15 F. Fan and A. J. Bard, J. Am. Chem. Soc., 1991, 95, 1969.

16 G. Chen, F. Zen, F. Fan and A. J. Bard, J. Phys. Chem., 1991, 95, 3682.

17 G. Wächtershäuser, Syst. Appl. Microbiol., 1988, 10, 207.
18 G. Wächtershäuser, Proc. Natl. Acad. Sci. USA, 1990, 87, 200.

19 G. Wächtershäuser, Origin Life Evol. Biochem., 1990, 20, 173.

20 G. Wächtershäuser, Royal Swedish Academy of Sciences Nobel Symposium, Oxford University Press, London, 1991, p. 239.

21 G. Wächtershäuser, Prog. Biophys. Mol. Biol., 1992, 58, 85.

22 G. Wächtershäuser, J. Pure Appl. Sci., 1993, 65, 1343.

23 M. A. A. Schoonen, Y. Xu and J. Bebie, Origin. Life Evol. Biochem., 1999, 29, 5.

24 J. S. Laskowski, in Colloid Chemistry in Mineral Processing, ed. J. S. Laskowski and J. Ralston, Elsevier, Amsterdam, 1992, p. 225.

25 J. Bebié, M. A. A. Schoonen, D. R. Strongin and M. Fuhrmann, Geochim. Cosmochim. Acta, 1998, 62, 633.

26 D. Fornasiero, V. Eijt and J. Ralston, Colloids Surf., 1991, 62, 63.

27 P. R. Holmes, F. K. Crundwell, Geochim. Cosmochim. Acta, 2000, 64, 263.

28 G. A. Somorjai, Introduction to surface chemistry, Wiley, New York, 1994.

29 J. Bebie and M. A. A. Schoonen, Earth Planet. Sci. Lett., 1999, 171,1 .

30 P. C. Hiemenz, Principles of colloid and surface chemistry, Marcel Dekker, New York, 1986.

31 K. Sasaki, Geochim. Cosmochim. Acta, 1994, 58, 4649.

32 J. Guevremont, D. R. Strongin and M. A. A. Schoonen, Surf. Sci., 1997, 391, 109.

33 J. M. Guevremont, D. R. Strongin and M. A. A. Schoonen, Am. Mineral., 1998, 83, 1246.

34 J. Guevremont, J. Bebié, A. R. Elsetinow, D. R. Strongin and M. A. A. Schoonen, Environ. Sci. Technol., 1998, 32, 3743.

35 J. M. Guevremont, A. R. Elsetinow, D. R. Strongin, J. Bebié and M. A. A. Schoonen, Am. Mineral., 1998, 83, 1353.

36 J. C. G. Walker and P. Brimblecombe, Precambrian Res., 1985, 28, 205.

37 D. R. Lowe, in Early Life on Earth, ed. S. Bengtson, Columbia University Press, New York, 1994, p. 24.

38 K. L. Von Damm, Seafloor Hydrothermal Systems, ed. S. E. Humphris, R. A. Zierenberg, L. S. Mullineaux and R. E. Thomson, American Geophysical Union, Washington, DC, 1995, p. 222.

39 E. L. Shock and C. M. Koretsky, Geochim. Cosmochim. Acta, 1993, 57, 4899.

40 E. L. Shock, Geochim. Cosmochim. Acta, 1992, 56, 3481.

41 E. L. Shock and C. M. Koretsky, Geochim. Cosmochim. Acta, 1995, 59, 1497.

42 D. A. Palmer and K. E. Hyde, Geochim. Cosmochim. Acta, 1993, 57, 1393.

43 P. Schindler, in Mineral-water interface geochemistry, ed. M. F. Hochella and A. F. White, American Mineralogical Society, Washington, DC, 1990, p. 281.

44 D. Kahne and W. C. Still, J. Am. Chem. Soc., 1988, 110, 7529.

45 D. L. Parkhurst, D. C. Thorstenson and N. L. Plummer, PHREEQE-A computer program for geochemical calculations, WRI, 80-96, US Geological Survey, Reston, VA, 1980.

46 A. E. Martell and R. M. Smith, Critical stability constants, Plenum Press, New York, 1974.

47 R. P. Schwarzenbach, P. M. Gschwend and D. M. Imboden, Environmental organic chemistry, Wiley-Interscience, New York, 1993.

48 K. M. Rosso, U. Becker and M. F. J. Hochella, Am. Mineral., 1999, 84, 1549.

49 J. A. Davis and D. B. Kent, in Mineral-water interface geochemistry, ed. M. F. Hochella and A. F. White, American Mineralogical Society, Washington, DC, 1990, p. 177.

50 Y. Xu, M. A. A. Schoonen and D. R. Strongin, Geochim. Cosmochim. Acta, 1996, 60, 4701.

51 M. A. A. Schoonen, Y. Xu and D. R. Strongin, J. Geochem. Explor., 1998, 62, 201.

52 Y. Xu and M. A. A. Schoonen, Geochim. Cosmochim. Acta, 1995, 59, 4605.

53 J. V. Smith, Proc. Natl. Acad. Sci. USA, 1998, 95, 3370.

54 M. A. A. Schoonen, A. Elsetinow, M. Borda and D. R. Strongin, Geochem. Trans., 2000, 4,

55 C. M. Eggleston, J. Ehrhardt and W. A. M. Stumm, Am. Mineral., 1996, 81, 1036.

56 M. A. A. Schoonen, N. S. Fisher and M. Wente, Geochim. Cosmochim. Acta, 1992, 56, 1801.

57 S. J. Sowerby and G. B. Peterson, Origin. Life Evol. Biochem., 1999, 29, 597. 